\title{
Microbiological, biochemical, physicochemical surface properties and biofilm forming ability of Brettanomyces bruxellensis
}

\author{
Maria Dimopoulou ${ }^{1} \cdot$ Margareth Renault ${ }^{2}$ - Marguerite Dols-Lafargue ${ }^{1,3} \cdot$ Warren Albertin $^{1,3} \cdot$ Jean-Marie Herry ${ }^{2}$. \\ Marie-Noëlle Bellon-Fontaine ${ }^{2} \cdot$ Isabelle Masneuf-Pomarede ${ }^{1,4}$
}

Received: 9 April 2019 / Accepted: 25 July 2019 / Published online: 3 September 2019

(C) Università degli studi di Milano 2019

\begin{abstract}
Purpose Brettanomyces bruxellensis is a serious source of concern for winemakers. The production of volatile phenols by the yeast species confers to wine unpleasant sensory characteristics which are unacceptable by the consumers and inevitably provoke economic loss for the wine industry. This ubiquitous yeast is able to adapt to all winemaking steps and to withstand various environmental conditions. Moreover, the ability of $B$. bruxellensis to adhere and colonize inert materials can be the cause of the yeast persistence in the cellars and thus recurrent wine spoilage. We therefore investigated the surface properties, biofilm formation capacity, and the factors which may affect the attachment of the yeast cells to surfaces with eight strains representative of the genetic diversity of the species.

Methods The eight strains of $B$. bruxellensis were isolated from different geographical and industrial fermentation origins. The cells were grown in synthetic YPD medium containing $1 \%(w / v)$ yeast extract (Difco Laboratories, Detroit), 2\% (w/v) bacto peptone (Difco), and 1\% (w/v) glucose. Surface physicochemical properties as electrophoretic mobility and adhesion to hydrocarbon of the cells were studied. The ability of the strains to form biofilm was quantified using a colorimetric microtiter 96-well polystyrene plate. Biochemical characteristics were examined by colorimetric methods as well as by chemical analysis.

Result Our results show that the biofilm formation ability is strain-dependent and suggest a possible link between the physicochemical properties of the studied strains and their corresponding genetic group.

Conclusion The capacity to detect and identify the strains of the spoilage yeast based on their biofilm formation abilities may help to develop more efficient cleaning procedures and preventing methods.
\end{abstract}

Keywords Brettanomyces bruxellensis $\cdot$ Wine spoilage $\cdot$ Biochemical properties $\cdot$ Physico-chemical surface properties $\cdot$ Biofilm formation

\section{Introduction}

The process of fermentation has been used for years to improve the shelf-life and the sensory properties of food and

Maria Dimopoulou

marouladimo@aua.gr

1 UR Oenologie EA 4577, USC 1366 INRA, Bordeaux INP, Université de Bordeaux, Bordeaux, France

2 UMR Génie et Microbiologie des Procédés Alimentaires, GMPA, AgroParisTech, INRA, Université Paris-Saclay,

78850 Thiverval-Grignon, France

3 ENSCBP, Bordeaux INP, 33600 Pessac, France

4 Ecole Nationale Supérieure des Sciences Agronomiques de Bordeaux-Aquitaine, Bordeaux, France beverages. Even if nowadays, the fermentation is often carried out from monocultures of a single fermentative strain, the traditional process usually involves a multitude of different microorganisms naturally present in the environment (Liu et al. 2017). These microorganisms produce a vast variety of aromatic molecules, and while some of them ameliorate the sensory profile and satisfy the consumers, some others cause sensory defects and product rejection (Belda et al. 2017; Tempère et al. 2018). The B. bruxellensis species may belong to both categories, depending on the production process and the final product characteristics. This yeast species can be desirable in kombucha and in certain beer style production (e.g., Belgium lambic), while in wine, it is considered as the source of major organoleptic defects (Chatonnet et al. 1992, 1995; Steensels et al. 2015). Actually, the capacity of B. bruxellensis to produce volatile phenols, which impart a "stable" or "horse-sweat" odor, can cause a drop in wine 
quality and in some cases the product becomes unfit for sale (Agnolucci et al. 2017).

Recently, the genome sequencing of B. bruxellensis demonstrated a great intraspecific genetic diversity and in particular, a variability of the ploidy level (Borneman et al. 2014; Fournier et al. 2017). A rapid, reliable, and discriminating method has been developed as a tool for genetic typing of B. bruxellensis strains using specific microsatellite markers (Albertin et al. 2014; Avramova et al. 2018a). Based on this method, a great number of $B$. bruxellensis isolates from various niches (beer, wine, cider, bioethanol, kombucha) and geographical areas were genotyped. The population structure analysis revealed three main genetic clusters and three subclusters associated with the strains ploidy level and substrates of isolation. Interestingly, the strain tolerance/resistance to sulfur dioxide, the main antimicrobial compound used in wine differs from one genetic cluster to the other, unraveling a strong link between genotype and this phenotypic trait (Avramova et al. 2018a, b). Other methods have been developed to control the spoilage yeast growth, as for example inactivation by heat or pressure, sterilizing filtration or through the use of ionized radiation (Delsart et al. 2016). However, these techniques are often expensive and may have a negative impact on sensory properties, which makes them incompatible with the production of high-quality wines. In addition, the majority of the current techniques do not systematically eliminate the entire population of $B$. bruxellensis or are ineffective when the cell population of the yeast is low (Guzzon et al. 2013). This situation may be explained by the high intraspecific genetic and phenotypic diversity observed within the yeast species that differentiates some strains and increases their adaptation mechanism (Di Toro et al. 2015; Guzzon et al. 2018). Indeed, the repeated use of high doses of the antimicrobial agent sulfur dioxide to control the development of $B$. bruxellensis during winemaking may have led to the emergence of more resistant strains which can tolerate the current used doses (Conterno et al. 2010; Curtin et al. 2012; Capozzi et al. 2016; Avramova et al. 2018b; Dimopoulou et al. 2019). Additionally, other wine stressors as ethanol, high sugar concentration, and temperature changes may also participate in the species adaptation mechanism involved in genetic diversity (Guzzon et al. 2018).

This yeast is able to survive and multiply in wine, especially in case of sluggish fermentation and difficulties of other species to monopolize the wine ecosystem (Renouf et al. 2006; Romano et al. 2008). Even if B. bruxellensis was detected at low level on grape berry, repetitive infections were observed in wine, suggesting that the cellar, rather than the vineyard, could be the main source of contamination (Garde-Cerdán and AncínAzpilicueta 2006; Barata et al. 2008; González-Arenzana et al. 2013; Rubio et al. 2015). Despite the fact that wine is not produced continuously throughout the year, yeast persistence in the cellars was demonstrated from year to year (Grangeteau et al. 2016). However, the mechanism by which yeasts persist in the winery is not yet elucidated.

Yeast cells possess a remarkable ability to adhere to abiotic surfaces, in particular in response to stress and nutrient limitation (Verstrepen and Klis 2006). Adhesion to surfaces and subsequent biofilm formation enable long-term survival of fungi and bacteria in unfavorable nutrient environments (Tek et al. 2018). Moreover, disinfectants are not able to penetrate the biofilm matrix, and possibly, the resistance to antimicrobial compounds or cleaning agents could be related to the ability of microorganism to form biofilm (Carpentier and Cerf 1993). Yeast adhesion is one of the most plastic and variable examined phenotype, while the attachment ability of closely genetic related strain could vary dramatically (Verstrepen and Klis 2006). Adhesion to abiotic surfaces is the first step in biofilm formation and depends on the physico-chemical properties of cells as well as of material surfaces. The cell surface properties are linked to the molecular composition of the wall and other external elements of the micro-organisms. In Saccharomyces cerevisiae, the attachment to plastic and mat formation requires Flo11p, a member of the large family of fungal cell surface glycoproteins (Reynolds and Fink 2001). The same authors showed that mat formation and cell architecture structure are modified as yeast ploidy level increases. Surface proteins such as adhesins can also increase the cell-surface hydrophobicity and promote hydrophobic interaction between the cells and abiotic surfaces (Kang and Choi 2005).

Joseph et al. (2007) showed that the majority of the B. bruxellensis isolates studied were able to produce biofilm onto polystyrene surface, upon long incubation time in the presence of low sugar concentration. However, this first study did not consider the genetic diversity of the species, nor the growth rate and yield of the studied strains.

In this paper, various methods were tested to examine the microbiological, biochemical, physicochemical surface properties and biofilm forming ability of a panel of strains of B. bruxellensis, representative of the species genetic diversity. A putative correlation between these different properties and the strain genotype has been examined.

\section{Materials and methods}

\section{Strains and growth conditions}

B. bruxellensis isolates were obtained from a variety of regions and fermented substrates, being part of the CRB Oenologie collection (Centre de Ressources Biologiques (Enologie, Bordeaux, France). The eight strains used in this study and their genetic group (Avramova et al. 2018a) are listed in Table 1. Their distribution on the genetic dendrogram is presented in Fig. 1. Firstly, all strains were spotted onto 
YPD medium containing 1\% $(w / v)$ yeast extract (Difco Laboratories, Detroit), $2 \%(w / v)$ bacto peptone (Difco), $1 \%$ $(w / v)$ glucose and agar $(20 \mathrm{~g} / \mathrm{L})$ and incubated for 5 days at $25^{\circ} \mathrm{C}$. One centimeter squared of solid culture was then inoculated into $40-\mathrm{mL}$ sterile Erlenmeyer flasks containing liquid YPD broth, placed at $25^{\circ} \mathrm{C}$ at $150 \mathrm{rpm}$, for $48 \mathrm{~h}$, and then transferred into $250-\mathrm{mL}$ liquid YPD culture for 10 days until the stationary growth phase, collected at density from 2,89 (strain L0417) to 4 (strain CBS 2499 and AWRI1608).

\section{Microbiological characteristics}

\section{Mat formation}

Yeast strains were evaluated for their ability for mat formation as described by Reynolds and Fink (2001), Briefly, $10 \mu \mathrm{L}$ of liquid culture of each yeast in YPD at $10^{6} \mathrm{UFC} / \mathrm{mL}$ was spotted with a toothpick onto YPD with $1.5 \%(w / v)$ agar (poured 1 day before with YPD agar). The plates were wrapped with parafilm to avoid evaporation, then incubated for 17 days at $25{ }^{\circ} \mathrm{C}$, and photographed using wide angle digital camera (Nikon, Coolpix P500). Analyses were performed in duplicate except for the strain GSP1504.

\section{Biofilm biomass quantification to polystyrene microtiter plates}

Biofilm formation was quantified using a colorimetric microtiter 96-well polystyrene plate (Thermo Scientific Nunc MicroWell) by a method adapted from O'Toole et al. (2000) (Tek et al. 2018). The eight strains were grown in YPD medium for 10 days until stationary growth phase and then inoculated in YPD or in wine-like medium (45\% Sauvignon juice, 50\% water, and 5\% ethanol). The OD of inoculum was spectrophotometrically adjusted to 0.1 at $600 \mathrm{~nm}$ in order to calibrate all the strains at a similar initial population level and cells were suspended in YPD or in wine-like medium. The inoculated media were aliquoted

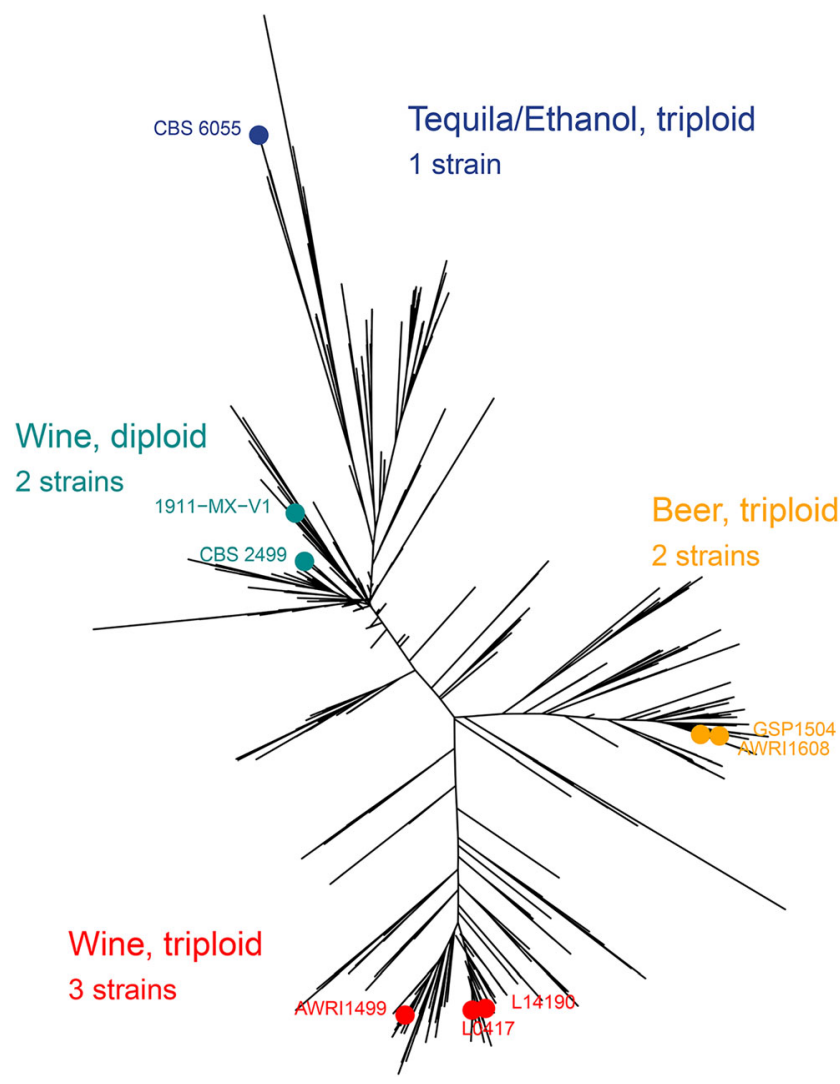

Fig. 1 Position of the eight B. bruxellensis strains in a dendrogram of 1488 strains (Avramova et al. 2018a)

$(200 \mu \mathrm{L})$ in polystyrene microplate wells. Each strain was inoculated in eight replicate wells in two separate plates, while eight negative control wells containing only broth were also included in each plate. The plates were incubated without any agitation at $25{ }^{\circ} \mathrm{C}$ for 15 days in a hermetic plastic box containing a glass of water to create a highly humid atmosphere and avoid evaporation. After 15 days of incubation, the suspended cell population was estimated by optical absorbance (OD $600 \mathrm{~nm}$ ) by using a single well in which the broth was mixed with a micropipette. The other wells were gently washed twice with $200 \mu \mathrm{L}$ of $0.9 \%(w / v)$
Table 1 The eight $B$. bruxellensis strains used in this study

\begin{tabular}{llll}
\hline Strain & Group color & Genetic group $^{\mathrm{a}}$ & Substrate of isolation \\
\hline AWRI1499 & Red & Triploid, wine & Red wine \\
L14190 & Red & Triploid wine & Red wine \\
L0417 & Red & Triploid wine & Red wine \\
1911-MX-V1 & Dark cyan & Diploid, wine & Red wine \\
CBS 2499 & Dar kcyan & Diploid, wine & Red wine \\
AWRI1608 & Orange & Triploid, beer & Red wine \\
GSP1504 & Orange & Triploid, beer & Beer \\
CBS 6055 & Blue & Triploid tequila/bioethanol & Beer \\
\hline
\end{tabular}

${ }^{\mathrm{a}}$ According to Avramova et al. 2018a 
$\mathrm{NaCl}$, dried in an inverted position and stained with $1 \%(w /$ $v$ ) crystal violet. The wells were rinsed again and the crystal violet was solubilized in $100 \mu \mathrm{L}$ of ethanol/acetone $(80: 20, v / v)$. The absorbance at $595 \mathrm{~nm}$ was determined using a microplate reader (Molecular devices).

\section{Biochemical characteristics}

\section{Cell lipid extraction}

After 10 days of growth in YPD medium, cells were collected and a sample corresponding to $2 \times 10^{9}$ cells was withdrawn. Cell concentration was estimated by flow cytometry and optical density (OD $600 \mathrm{~nm}$ ). Then, each sample was washed twice with distilled water, frozen with liquid nitrogen, and conserved at $-20{ }^{\circ} \mathrm{C}$ in Eppendorf tubes. From the frozen samples obtained previously, the membrane lipid extraction was realized according to the protocol of Tronchoni et al. (2012) with some slight modifications. In each tube, $1 \mathrm{~g}$ of glass beads ( $0.5 \mathrm{~mm}$, Biospec Products), $700 \mu \mathrm{L}$ of cold methanol, and $140 \mu \mathrm{L}$ of EDTA $0.1 \mathrm{M}$ were added and vigorously mixed $(4 \times 45 \mathrm{~s})$ in a mini-bead-beater- 8 (Biospec Products, Qiagen). By this way, the cell membrane wall was completely disordered and the liquid phase was separated from the glass beads by centrifugation and transferred into a $15-\mathrm{mL}$ glass screw tube. Lipid extraction was performed in three steps, starting with the addition of $2.5 \mathrm{~mL}$ chloroform/methanol (1:1, $v / v$, for $45 \mathrm{~min})$, centrifugation (3000 rpm, $5 \mathrm{~min})$, and recuperation of the inferior phase. Then, $2.5 \mathrm{~mL}$ of chloroform/methanol $(2: 1, v / v$, for $45 \mathrm{~min})$ was added, and the inferior phase was recuperated as before. The last extraction was realized by adding $2.5 \mathrm{~mL}$ chloroform/methanol (1:2, $v / v$, for $45 \mathrm{~min}$ ). The inferior organic phases was transferred to a $15-\mathrm{mL}$ glass screw tube and cleaned twice by adding $\mathrm{KCl}$ $0.88 \%$ (1/4 of a total volume of the extract). After vortexing and cooling at $4{ }^{\circ} \mathrm{C}$ for $30 \mathrm{~min}$, the samples were centrifuged (3000 rpm, $5 \mathrm{~min}$ ) and the inferior organic phase was collected and stored at $-80^{\circ} \mathrm{C}$ until analysis.

\section{Fatty acid determination}

The extracted lipids were concentrated to dryness under nitrogen stream and then methylated by the presence of methanol and sulfuric acid $(5 \% \mathrm{v} / \mathrm{v})$ for $2 \mathrm{~h}$ at $85^{\circ} \mathrm{C}$ in the presence of $50 \mu \mathrm{g}$ heptanoic acid (Sigma-Aldrich) as internal standard. Then, the addition in the same tube of $1 \mathrm{~mL}$ of $\mathrm{NaCl}(2.5 \%$ $w / v)$ and $2 \mathrm{~mL}$ of hexane enabled the extraction of methylic esters from the fatty acids, which were concentrated to dryness under nitrogen stream. Finally, $200 \mu \mathrm{L}$ of hexane was added to fatty acid extract and their relative concentrations were determined by gas chromatography coupled with flame ionization, as described by Redón et al. (2009).

\section{Exopolysaccharide quantification}

After 10 days of growth in YPD broth, soluble exopolysaccharides (EPS) liberated by the yeasts were collected in the culture supernatant. The total excreted polysaccharides were precipitated (Dimopoulou et al. 2016) and their concentration was determined according to the anthronesulfuric acid method with glucose as standard (Ludwig and Goldberg 1956). For each sample, the polymer precipitation and assays were done in triplicate. The EPS quantification results were normalized by the cell population after 10 days of growth (OD $600 \mathrm{~nm})$.

\section{Surface physicochemical properties}

\section{Preparation of yeast suspension characteristics}

The physicochemical characterization of B. bruxellensis strains was carried out for cells grown in YPD broth. Briefly, cells were harvested by centrifugation (Eppendorf) at $4{ }^{\circ} \mathrm{C}$ for $10 \mathrm{~min}$ at $7000 \mathrm{~g}$ and then washed twice with and re-suspended in the relevant suspending liquid $(\mathrm{NaCl}$ $150 \mathrm{mM}$ or $1.5 \mathrm{mM}$ ). All experiments were performed on three separately grown cultures.

\section{Measurement of electrophoretic mobility (EM)}

The electrophoretic mobility (EM) of yeast in a sodium chloride solution $(1.5 \mathrm{mM})$ was measured as a function of the $\mathrm{pH}$ within the range of 2 to 5 , adjusted by the addition of $\mathrm{HNO}_{3}$. The concentration of the suspension was approximately at $10^{7}$ cells $/ \mathrm{mL}$. Measurements were taken in a $50 \mathrm{~V} / \mathrm{cm}$ electric field with a laser zetameter (CAD Instruments, France). For each measurement, results were based on the automated video analysis of about 200 cells. Each experiment was performed twice.

\section{Microbial adhesion to hydrocarbon}

Microbial adhesion to hydrocarbon (MATH) enables the evaluation of the hydrophobic/hydrophilic character of the cell surface of $B$. bruxellensis strains (Bellon-Fontaine et al. 1996). Experimentally, yeast suspension (1.5 mL) was mixed with $0.25 \mathrm{~mL}$ of each solvent (hexadecane, decane). The mixture was stirred for $2 \mathrm{~min}$ to form an emulsion and a rest period of $15 \mathrm{~min}$ allowed the complete separation of the two phases. The optical density (OD) of the aqueous phase and that of the initial cell suspension $\left(\mathrm{OD}_{0}\right)$ were measured at $400 \mathrm{~nm}$. The microbial affinity to each solvent was calculated using the formula: 
$\%$ affinity $=\left(1-\frac{O D}{O D_{0}}\right) \times 100$

Each experiment was performed twice.

\section{Statistical analysis}

Kruskal-Wallis statistical test (agricolae package, $\mathrm{R}, p$ value $<$ 0.05 ) and principal component analysis (PCA) were performed using R-package.

\section{Results}

\section{Microbiological characteristics}

Eight strains of $B$. bruxellensis belonging to distinct genetic groups were used: two diploid strains (belonging to the genetic group dark cyan, CBS2499_like), three triploid strains (red group AWRI1499_like), two triploid strains (orange group AWRI1608_like), and a triploid tequila/bioethanol group strain (blue group, CBS5512 like) (Table 1, Fig. 1).

The mat formation of the eight strains was observed after 17 days on YPD plate (Fig. 2). The diameter of the mats varied between $9 \mathrm{~mm}$ (1911-MX-V1) and $15 \mathrm{~mm}$ (CBS 6055). All the other strains displayed mats with a diameter ranging from 11 to $13 \mathrm{~mm}$. CBS 6055 was the only strain exhibiting mat with rough edges. No relation between ploidy level and preliminary mat formation was observed.

The B. bruxellensis strains were then studied for their biofilm forming ability in polystyrene microtiter plates, in two different media, YPD and a Sauvignon must derive wine-like medium. As shown in Fig. 3, the medium composition changed significantly the biofilm formation ability of the strains belonging to the dark cyan, red, and blue genetic groups. More precisely, all the strains in these groups

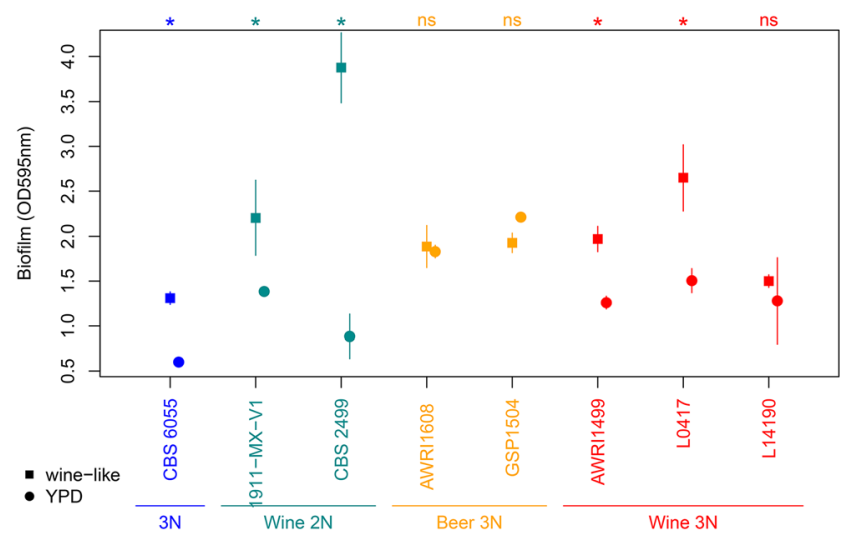

Fig. 3 Biofilm formation ability of the eight B. bruxellensis strains in two different growth media; wine like and YPD. The colors represent the genetic group of the strains. Upper stars or "NS" denote, respectively, significant difference between media or "non-significance" as defined by Kruskal-Wallis statistical test (agricolae package, $\mathrm{R}, p$ value $<0.05$ )

expressed increased biofilm capacity in wine-like medium compared with in YPD broth. On the contrary, the two strains in the orange genetic group showed a similar performance in wine-like and YPD broth. Furthermore, in wine-like medium, the strain CBS 2499 displayed the highest biofilm formation ability whereas CBS 6055 displayed the lowest biofilm formation ability.

\section{Biochemical characteristics}

\section{Fatty acid composition}

Fatty acid content was also studied in the eight selected strains. The total fatty acid content was in the same order of magnitude for the eight strains. However, the strains differed by the fatty acid proportions. Interestingly, the SFA (saturated fatty acids) to MUFA (monounsaturated fatty acids) ratio was similar for each genetic subpopulation studied (Fig. 4). The highest content of SFAs, $91 \%$ of the total membrane fatty acids amount, was observed for the strains L14190, L0417, and AWRI1499. These three strains belonging to the red genetic group were significantly different from most of the strains in the other groups, with a mean SFA/MUFA ratio more than twice higher than the ratio of the other three genetic
Fig. 2 Photos of colony morphology taken by camera of the eight tested strains of B. bruxellensis after 17 days of growth at YPD plate
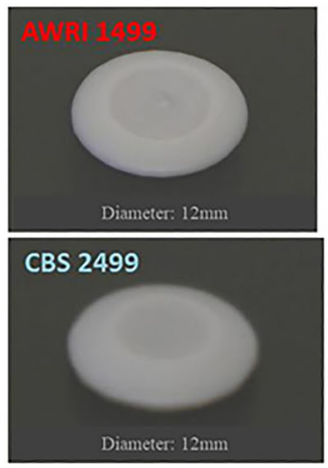
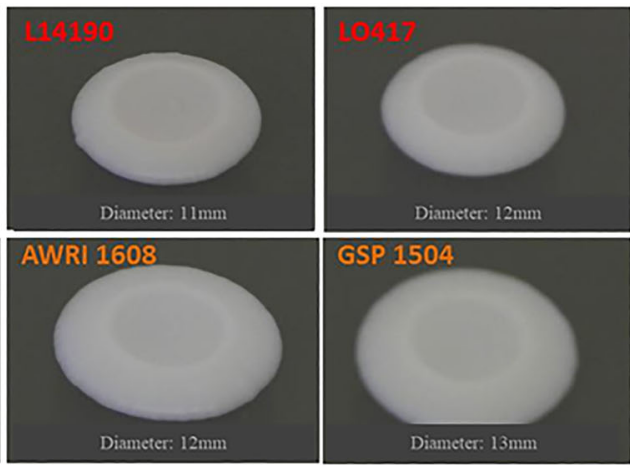

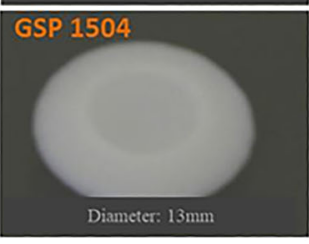




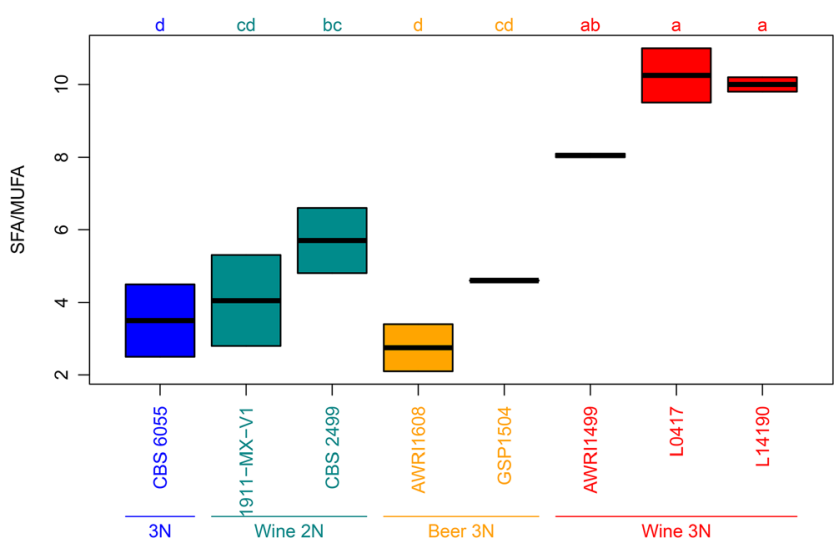

Fig. 4 Ratio of saturated fatty acid to monounsaturated fatty acid of the eight tested strains of $B$. bruxellensis. The colors represent the genetic group of the strains. Upper letters represent significance groups as defined by Kruskal-Wallis statistical test (agricolae package, $\mathrm{R}, p$ value $<0.05$ )

groups. On the contrary, the strain AWRI1608 showed the lowest ratio level, composed at $73 \%$ of SFA.

\section{Exopolysaccharide production}

The $B$. bruxellensis strains were examined for their ability to liberate exopolysaccharides (EPS) after growth in YPD medium for 10 days until reaching stationary growth phase. The results are presented as the ratio of total amount of EPS $(\mathrm{mg} / \mathrm{L})$ produced to the cell population (OD at $600 \mathrm{~nm})$ (Fig. 5). The best-producing strains were CBS 6055 and L0417, which liberated more than $100 \mathrm{mg} / \mathrm{L} / \mathrm{OD}$ of soluble exopolysaccharides in the culture medium. On the other hand, the strain 1911-MX-V1 liberated less than $40 \mathrm{mg} /$ L/OD of EPS. Even if the EPS production ability of the eight studied strains could not be significantly distinguished according to their genetic group, the strains of the dark cyan genetic group displayed the lower EPS liberating ability, with a mean production of $51.5 \mathrm{mg} / \mathrm{L} / \mathrm{OD}$.

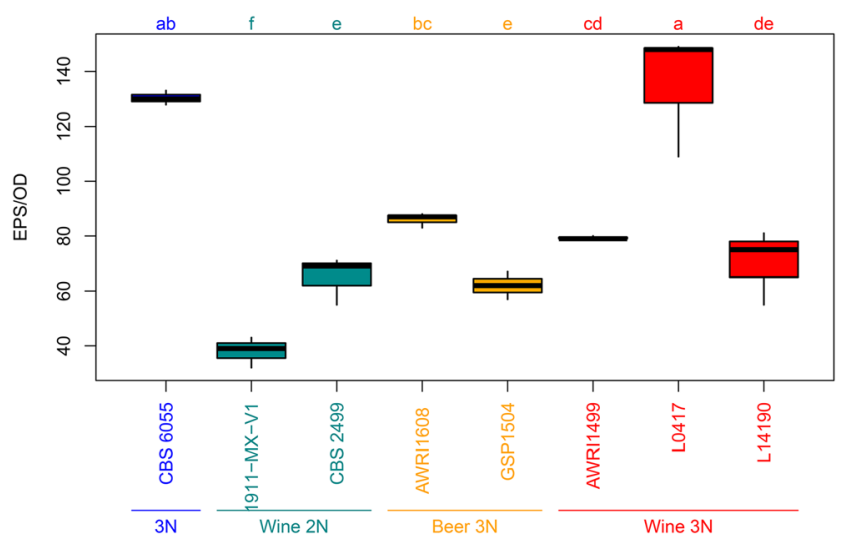

Fig. 5 Exopolysaccharide production of the eight tested strains of B. bruxellensis. The colors represent the genetic group of the strains. Upper letters represent significance groups as defined by KruskalWallis statistical test (agricolae package, $\mathrm{R}, p$ value $<0.05$ )

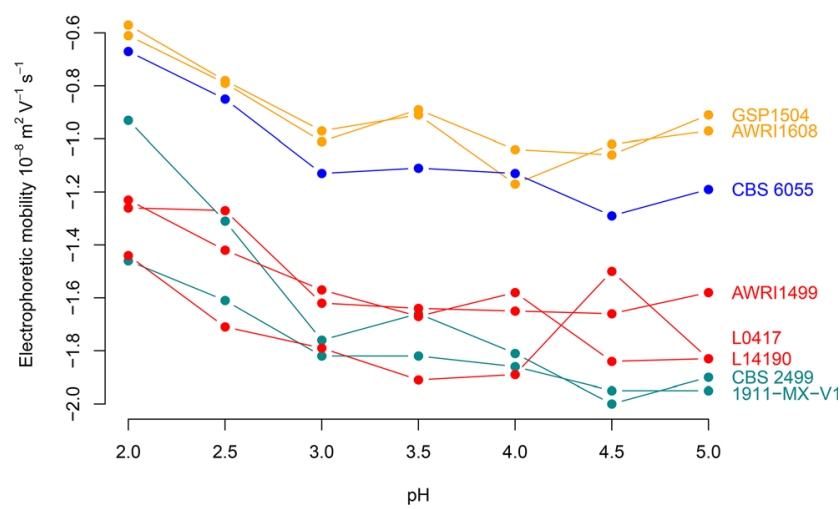

Fig. 6 Electrophoretic mobility according to the $\mathrm{pH}$ of the eight strains of B. bruxellensis. The colors represent the genetic group of the strains. The standard deviations of EM do not exceed 0.2 for all yeasts

\section{Surface physicochemical characteristics}

The electrophoretic mobilities (EM) of the eight B. bruxellensis strains were measured at seven different $\mathrm{pH}$ values (from 2 to 5). The EM values of each strain suspended in $1.5 \mathrm{mM} \mathrm{NaCl}$ revealed negatively charged cells at $\mathrm{pH}$ values between 2 and 5 (Fig. 6). No isoelectric point could be determined within the range of $\mathrm{pH}$ values investigated but a reduction in mobility could be observed at $\mathrm{pH} 2$. In our experimental conditions and whatever the tested $\mathrm{pH}$, AWRI 1608, GSP 1504, and CBS 6055 (orange and blue genetic group) exhibited greater electronegativity than AWRI 1499, L0417, L14190, CBS 2499, and 1911-MX-V (red and dark cyan genetic group). Moreover, from an oenological point of view, in wine conditions ( $\mathrm{pH}$ close to 3.5 ), the two strains from the orange genetic group were the less electronegative.

The eight $B$. bruxellensis strains were also assayed for their affinity to apolar solvents, decane and hexadecane, with the MATH analysis test. According to our results, the affinity of B. bruxellensis strains for hexadecane or decane values ranged from 0 to $25.6 \%$ (Table 2) reflecting hydrophilic surface characteristics. It could be noted that in the dark cyan group, only CBS 2499 strain displayed the higher affinity for both solvents.

\section{PCA}

Principal component analysis of combined data is shown in Fig. 7. In this representation, the abscissa represented $38.5 \%$ of the total variation from the original data set and was mainly correlated with a lower negative charge of yeast cells and the mat formation. The ordinate, which represented $29.6 \%$ of the total variation from the original data set, was mainly correlated with EPS production. This axis was also negatively correlated with yeast cell affinity for nonpolar solvents as well as biofilm formation in wine. This principal component analysis clearly distinguishes the yeast strains according to their genetic group. 
Table 2 Percentage of affinity to the hexadecane and decane used in the MATH analysis for the eight $B$. bruxellensis strains studied. The standard deviations of $\%$ affinity do not exceed 0.5

\begin{tabular}{lllllllll}
\hline $\begin{array}{l}\text { Strains } \\
\text { Solvent }\end{array}$ & 1911-MX-V1 & CBS 2499 & AWRI1499 & L0417 & L14190 & AWRI1608 & GSP1504 CBS 6055 \\
\hline$\%$ HD & 0 & 21.5 & 0 & 0 & 0 & 1.7 & 8.1 & 0.3 \\
$\%$ D & 0 & 25.6 & 0 & 0 & 0 & 2.8 & 11.9 & 2.9 \\
\hline
\end{tabular}

\section{Discussion}

In this study, different protocols were developed and applied in order to examine the microbiological, biochemical, physicochemical surface properties and biofilm forming ability of a panel of strains of $B$. bruxellensis, representative of the species genetic diversity. Considering the high intra-species genetic diversity of $B$. bruxellensis, our study considered isolates representative of the different genetic groups of the species (Avramova et al. 2018a).

Different mat diameters and aspect were reported for the first time. By using isogenic strains from haploid to tetraploid of Saccharomyces, Reynolds and Fink (2001) reported an inverse relation between ploidy level and mat formation. No such relationship has been observed in this study. However, mat diameter has been correlated with the yeast surface charge related to the genetic group. In the same way and depending on the genetic group, the biofilm formation into polystyrene wells was differently affected by the growth medium. Saccharomyces cerevisiae biofilm forming ability was shown to be linked to glucose levels, with a reduction in complete absence of glucose (Reynolds and Fink 2001). This was shown to depend to FLO11 transcription and glucose repression (Gagiano et al. 1999). In our experimental condition, glucose but also ethanol levels were higher in winelike medium compared to YPD, and two strains (1911-MX-V1 and CBS 2499) showed higher biofilm forming ability in the medium with the highest glucose concentration. However, opposite results were obtained for the two strains of the orange genetic group as biofilm formation ability was not significantly modulated by medium composition as noticed for the other strains, thus suggesting different adhesion or regulation mechanisms according to the genetic group considered. While the wine-like medium we used here is different from an actual wine, these results outline that environments trigger different responses for traits of oenological interest. The key factors could be identified through experiments in various environments and/or different wines.

Interestingly, this is the first time that the membrane total free fatty acid composition and the exopolysaccharide liberation capacity of the species have been studied. The total free fatty acid membrane composition has been used in the past as a typing method (Rozès et al. 1992) and was shown to pay an important role in the cell permeability and adaptation mechanism especially under hostile environmental conditions like wine. Genes involved in lipid metabolism were showed to be enriched in B. bruxellensis genome with some genes that may contribute to ethanol tolerance of the species (Woolfit et al. 2007). Recent study showed that the presence of sulfites leads to increased cell permeability (Longin et al. 2016). The three strains of the red genetic group are composed of a higher ratio of SFA/MUFA compared to the other genetic groups. Taking into consideration that this genetic group gathered mainly tolerant/resistant strains to high concentration of sulfur dioxide (Avramova et al. 2018a), a link between the two tested phenotypic traits but also with the genetic group could be suggested. Regarding end-point exopolysaccharide liberation, the strains CBS 6055 and L0417 displayed the highest production capacity, which may be due to either distinct mannoprotein composition or cell wall dynamics
Fig. 7 Principal component analysis of combined data
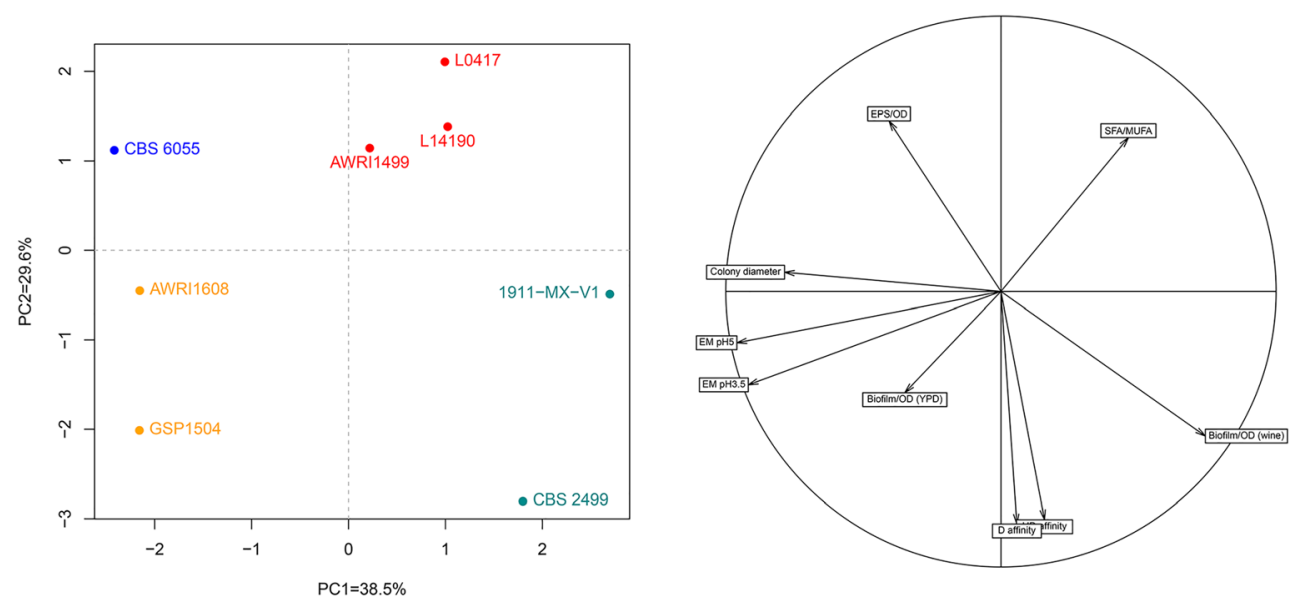
or to premature cell lysis compared to other strains. Nevertheless, as the mechanism in biofilm formation is complex, a direct link between the total amount of EPS and biofilm formation cannot be made for the studied strains. Differences are also noted concerning the physicochemical properties of the eight yeasts analyzed which all presented hydrophilic and negatively charged profiles. Indeed, EM measurements clearly indicate a greater electronegativity of the strains of the orange and blue genetic group in comparison with strains of red or dark cyan genetic group. All these results suggest distinct wall composition and metabolism traits which can possibly affect the biofilm production capacity. Indeed, the wall polysaccharides are the first and most abundant component of the cell which comes in contact with the surfaces and can affect the microbial colonization ability (Ghafoor et al. 2011; Sheppard and Howell 2016). According to previous studies, they may contribute positively or negatively to biofilm formation (Verstrepen and Klis 2006; Legras et al. 2016). From a general point of view, even if the strain number was low, our present study confirmed the fact that $B$. bruxellensis shows a great variability not only at genetic but also phenotypic level. The tested strains are clearly different regarding their cell surface properties and this may have significant consequences, firstly on their ability to primarily adhere to surfaces and secondly on their biofilm formation capacity. Additional work with a higher number of strains representative of the genetic groups and a close examination of the biofilm formation steps is now needed. A simple method, based on PCR, is now available to identify the strains contaminating the cellar (Albertin et al. 2017). Thus, the prediction of their $B$. bruxellensis persistence abilities seems to be an indispensable tool for the winemakers in order to better adapt their winemaking techniques and especially their cleaning procedures.

Funding This work was supported by funds from FranceAgriMer. Lipids analysis was performed at the lipidomic plateform of Bordeaux University.

\section{Compliance with ethical standards}

Conflict of interest The authors declare that they have no conflict of interest.

Ethical approval This work does not contain any studies with human participants or animals performed by any of the authors.

Informed consent Informed consent was obtained from all individual participants included in the study. The study has been also published as a preprint version with doi https://doi.org/10.1101/579144.

\section{References}

Agnolucci M, Tirelli A, Cocolin L, Toffanin A (2017) Brettanomyces bruxellensis yeasts: impact on wine and winemaking. World $\mathrm{J}$ Microbiol Biotechnol 33(10):180
Albertin W, Panfili A, Miot-Sertier C, Goulielmakis A, Delcamp A, Salin F, Lonvaud-Funel A, Curtin C, Masneuf-Pomarede I (2014) Development of microsatellite markers for the rapid and reliable genotyping of Brettanomyces bruxellensis at strain level. Food Microbiol 42:188-195

Albertin W, Masneuf-Pomarede I, Peltier E (2017) Method for analysing a sample to detect the presence of sulphite-resistant yeasts of the Brettanomyces bruxellensis species and kit for implementing same. France patent no. PCT/FR2016/052701

Avramova M, Cibrario A, Peltier E, Coton M, Coton E, Schacherer J, Spano G, Capozzi V, Blaiotta G, Salin F, Dols-Lafargue M, Grbin P, Curtin C, Albertin W, Masneuf-Pomarede I (2018a) Brettanomyces bruxellensis population survey reveals a diploid-triploid complex structured according to substrate of isolation and geographical distribution. Sci Rep 8(1):4136

Avramova M, Vallet-Courbin A, Maupeu J, Masneuf-Pomarède I, Albertin W (2018b) Molecular diagnosis of Brettanomyces bruxellensis sulfur dioxide sensitivity through genotype specific method. Front Microbiol 9:1260

Barata A, Caldeira J, Botelheiro R, Pagliara D, Malfeito-Ferreira M, Loureiro V (2008) Survival patterns of Dekkera bruxellensis in wines and inhibitory effect of Sulphur dioxide. Int J Food Microbiol 121:201-207

Belda I, Zarraonaindia I, Perisin M, Palacios A, Acedo A (2017) From vineyard soil to wine fermentation: microbiome approximations to explain the "terroir" concept. Front Microbiol 8:821

Bellon-Fontaine MN, Rault J, Van Oss C (1996) Microbial adhesion to solvents: a novel method to determine the electron-donor/electronacceptor or Lewis acid-base properties of microbial cells. Colloids Surf B: Biointerfaces 7:47-53

Borneman AR, Zeppel R, Chambers PJ, Curtin CD (2014) Insights into the Dekkera bruxellensis genomic landscape: comparative genomics reveals variations in ploidy and nutrient utilisation potential amongst wine isolates. PLoS Genet 13(2):10

Capozzi V, Di Toro MR, Grieco F, Michelotti V, Salma M, Lamontanara A, Russo P, Orrù L, Alexandre H, Spano G (2016) Viable but not Culturable (VBNC) state of Brettanomyces bruxellensis in wine: new insights on molecular basis of VBNC behaviour using a transcriptomic approach. Food Microbiol 59:196-204

Carpentier and Cerf (1993) Biofilms and their consequences with particular reference to hygiene in the food industry, J Appl Bacteriol 75: 499-511

Chatonnet P, Dubourdieu D, Boidron JN (1992) Incidence des conditions de fermentation et d'élevage des vins blancs secs en barriques sur leur composition en substances cédées par le bois de chêne. Sci Aliment 12:665-685

Chatonnet P, Dubourdieu D, Boidron JN (1995) The influence of Brettanomyces/Dekkera sp. yeasts and lactic acid Bacteria on the Ethylphenol content of red wines. Am J Enol Vitic 46:463-468

Conterno L, Fondazione E, Henick-Kling T (2010) Brettanomyces/ Dekkera off-flavours and other wine faults associated with microbial spoilage, in: Reynolds, a.G. (Ed.), managing wine quality, Woodhead publishing series in food science, technology and nutrition. Reynolds, Andrew G. managing wine quality. Am J Enol Vitic 57:139-147

Curtin C, Kennedy E, Henschke PA (2012) Genotype-dependent sulphite tolerance of Australian Dekkera (Brettanomyces) bruxellensis wine isolates. Lett Appl Microbiol 55:56-61

Delsart C, Grimi N, Boussetta N, Miot Sertier C, Ghidossi R, Vorobiev E, Mietton PM (2016) Impact of pulsed-electric field and high-voltage electrical discharges on red wine microbial stabilization and quality characteristics. J Appl Microbiol 120:152-164

Di Toro MR, Capozzi V, Beneduce L, Alexandre H, Tristezza M, Durante M, Spano G (2015) Intraspecific biodiversity and 'spoilage potential' of Brettanomyces bruxellensis in Apulian wines LWT-Food Science and Technology 60(1):102-108 
Dimopoulou M, Bardeau T, Ramonet PY, Miot-Certier C, Claisse O, Doco T, Petrel M, Lucas P, Dols-Lafargue M (2016) Exopolysaccharides produced by Oenococcus oeni: from genomic and phenotypic analysis to technological valorization. Food Microbiol 53:10-17

Dimopoulou M, Hatzikamari M, Masneuf-Pomarede I, Albertin W (2019) Sulfur dioxide response of Brettanomyces bruxellensis strains isolated from Greek wine. Food Microbiol 78:155-163

Fournier T, Gounot JS, Freel K, Cruaud C, Lemainque A, Aury JM, Wincker P, Schacherer J, Friedrich A (2017) High-Quality de Novo Genome Assembly of the Dekkera bruxellensis Yeast Using Nanopore MinION Sequencing. G3 (Bethesda) 7(10):3243-3250

Gagiano M, van Dyk D, Bauer F, Lambrechts MG, Pretorius IS (1999) Msn1p/Mss10p, Mss11p and Muc1p/Flo11p are part of a signal transduction pathway downstream of Mep2p regulating invasive growth and pseudohyphal differentiation in Saccharomyces cerevisiae. Mol Microbiol 31:103-116

Garde-Cerdán T, Ancín-Azpilicueta C (2006) Review of quality factors on wine ageing in oak barrels. Trends Food Sci Technol 17:438-447

Ghafoor A, Hay ID, Rehm BHA (2011) Role of exopolysaccharides in Pseudomonas aeruginosa biofilm formation and architecture. Appl Environ Microbiol 77:5238-5246

González-Arenzana L, Santamaría P, López R, Garijo P, Gutiérrez AR, Garde-Cerdán T, López-Alfaro I (2013) Microwave technology as a new tool to improve microbiological control of oak barrels: a preliminary study. Food Control 30:536-539

Grangeteau C, Gerhards D, von Wallbrunn C, Alexandre H, Rousseaux S, Guilloux-Benatier M (2016) Persistence of two non-Saccharomyces yeasts (Hanseniaspora and Starmerella) in the cellar. Front Microbiol 7:268

Guzzon R, Nardin T, Micheletti O, Nicolini G, Larcher R (2013) Antimicrobial activity of ozone. Effectiveness against the main wine spoilage microorganisms and evaluation of impact on simple phenols in wine. Aust J Grape Wine Res 19:180-188

Guzzon R, Larcher R, Guarcello R, Francesca N, Settanni L, Moschetti G (2018) Spoilage potential of brettanomyces bruxellensis strains isolated from Italian wines. Food Res Int 105:668-677

Joseph L, Kumar G, Su E, Bisson LF (2007) Adhesion and biofilm production by wine isolates of Brettanomyces bruxellensis. Am J Enol Vitic 58:373-378

Kang S, Choi H (2005) Effect of surface hydrophobicity on the adhesion of $S$. cerevisiae onto modified surfaces by poly (styrene-ran-sulfonic acid) random copolymers. Colloids Surf B: Biointerfaces 46:70-77

Legras JL, Moreno-Garcia J, Zara S, Zara G, Garcia-Martinez T, Mauricio JC, Mannazzu I, Coi AL, Bou Zeidan M, Dequin S, Moreno J, Budroni M (2016) Flor yeast: new perspectives beyond wine aging. Front Microbiol 7:503

Liu Y, Rousseaux S, Tourdot-Maréchal R, Sadoudi M, Gougeon R, Schmitt-Kopplin P, Alexandre H (2017) Wine microbiome: a dynamic world of microbial interactions. Crit Rev Food Sci Nutr 57: 856-873

Longin C, Degueurce C, Julliat F, Guilloux-Benatier M, Rousseaux S, Alexandre H (2016) Efficiency of population-dependent sulfite against Brettanomyces bruxellensis in red wine. Food Res Int 89: $620-630$

Ludwig TG, Goldberg HJV (1956) The Anthrone method for the determination of carbohydrates in foods and in Oral rinsing. J Dent Res 35(1):90-94

O’Toole G, Kaplan HB, Kolter R (2000) Biofilm formation as microbial development. Annu Rev Microbiol 54:49-79

Redón M, Guillamón JM, Mas A, Rozès N (2009) Effect of lipid supplementation upon Saccharomyces cerevisiae lipid composition and fermentation performance at low temperature. Eur Food Res Technol 228:833-840

Renouf V, Falcou M, Miot-Sertier C, Perello MC, De Revel G, LonvaudFunel A (2006) Interactions between Brettanomyces bruxellensis and the other yeast species during the first steps of winemaking. J Appl Microbiol 100:1208-1219

Reynolds T, Fink GR (2001) Bakers' yeast, a model for fungal biofilm formation. Science 291:878-881

Romano A, Perello MC, de Revel G, Lonvaud-Funel A (2008) Growth and volatile compound production by Brettanomyces/Dekkera bruxellensis in red wine. J Appl Microbiol 104(6):1577-1585

Rozès N, Garcìa-Jares C, Larue F, Lonvaud-Funel A (1992) Differentiation between fermenting and spoilage yeasts in wine by total free fatty acid analysis. J Sci Food Agric 59:351-357

Rubio P, Garijo P, Santamaria P, Lopez R, Martinez J, Gutierrez A (2015) Influence of oak origin and ageing on wine spoilage by Brettanomyces yeasts. Food Control 54:176-180

Sheppard DC, Howell PL (2016) Biofilm exopolysaccharides of pathogenic Fungi: lessons from Bacteria. J Biol Chem 291:12529-12537

Steensels J, Daenen L, Malcorps P, Derdelinckx G, Verachtert H, Verstrepen KJ (2015) Brettanomyces yeasts-from spoilage organisms to valuable contributors to industrial fermentations. Int J Food Microbiol 206:24-38

Tek EL, Sundstrom JF, Gardner JM, Oliver SG, Jiranek V (2018) Evaluation of the ability of commercial wine yeasts to form biofilms (mats) and adhere to plastic: implications for the microbiota of the winery environment. FEMS Microbiol Ecol 94(2):fix188

Tempère S, Marchal A, Barbe JC, Bely M, Masneuf-Pomarede I, Marullo P, Albertin W (2018) The complexity of wine: clarifying the role of microorganisms. Appl Microbiol Biotechnol 102:3995-4007

Tronchoni J, Rozès N, Querol A, Guillamón JM (2012) Lipid composition of wine strains of Saccharomyces kudriavzevii and Saccharomyces cerevisiae grown at low temperature. Int J Food Microbiol 155:191-198

Verstrepen KJ, Klis FM (2006) Flocculation, adhesion and biofilm formation in yeasts. Mol Microbiol 60:5-15

Woolfit M, Rozpedowska E, Piskur J, Wolfe KH (2007) Genome survey sequencing of the wine spoilage yeast Dekkera (Brettanomyces) bruxellensis. Eukaryot Cell 6:721-733

Publisher's note Springer Nature remains neutral with regard to jurisdictional claims in published maps and institutional affiliations. 